\title{
A Combinatorial Antihypertensive Drug (Reserpine and Hydrazine) Does Not Cause Severe Depression
}

\author{
Radhika Rajkumar ${ }^{1}$, Alex Divya Merciline ${ }^{2}$, Suresh Kumar Muthukrishnan ${ }^{2,3}$, Murali Subhashree ${ }^{1}$, Manjula Datta $^{3}$ \\ and Jamuna R Subramaniam ${ }^{1 *}$
}

${ }^{1}$ Center for Preclinical and Translational Medicine Research, Central Research Facility, Sri Ramachandra University, India

${ }^{2}$ Department of Clinical Psychology, Sri Ramachandra Institute of Higher Education and Research, India

${ }^{3}$ Department of Clinical Psychology, Composite Regional Center for Persons with Disabilities (NIEPMD), India

*Corresponding author: Jamuna R Subramaniam, Associate Professor, Center for Preclinical and Translational Medicine Research Central Research Facility, Sri Ramachandra Medical College and Research Institute (Deemed University), Chennai 600 116, India

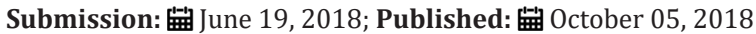

\begin{abstract}
Background and objectives: Reserpine, a traditional Indian Ayurvedic medicine, is approved by the FDA to treat hypertension and for treatment resistant psychosis. The major reported side effect of reserpine is depression. Hence, hypertensive patients on prolonged reserpine treatment were evaluated for occurrence of depression.

Methods: One-time cross-sectional evaluation was done in 104 subjects on reserpine and 105 controls, who were matched for age (majority being between 50- 70 years old), sex, education, and social background. The Control group had no chronic disease and the treatment group comprised of hypertensive patients who had received reserpine as Adelphane (0.1mg reserpine and 10mg of hydralazine) or Adelphane Esidrex [Novaritis (Basel, Switzerland)] for more than 1 year. Both the groups were asked to answer (and were rated by) Hamilton Depression Rating Scale (HDRS-17-items version). The results were scored, statistically analyzed and plotted with Sigma Plot.
\end{abstract}

Results: Results obtained by the HDRS were classified into normal, and different levels of depression by score-based categorization. Of the 105 control and 104 treated patients, 38\% (both control and treated) were normal, 38\% control and $48 \%$ treated had mild depression while $23.8 \%$ control and $13.4 \%$ treated had moderate depression. No severe or very severe depression in control or treated group was found.

Interpretation and Conclusion: Reserpine does not cause depression even when taken for years. The study is small with $\sim 100$ subjects per group. As a proven antihypertensive drug, our results should pave the way to bring reserpine into the mainstream..

Keywords: Reserpine; Depression; Hamilton depression scale; Hypertension; Antihypertensive drug

\section{Introduction}

Hypertension is one of the most common non-communicable chronic diseases. More than a billion people in the world are hypertensive [1]. Hypertension is a silent killer causing premature mortality [2]. Unlike other diseases, the risk for hypertension exists in all adults (starting from 25 years) and is frequent from middle age (40 years) [3]. Uncontrolled blood pressure leads to heart disease, stroke and kidney failure [4], causing untimely mortality and disability. Impairment of blood circulation in the brain can cause several neurological complications including cognitive impairment. In fact, vascular dementia is quite common. In addition, hypertension is disproportionally more prevalent in low- and middle-income countries [5]. Hence, an effective public health initiative to identify, control and treat hypertension is an urgent necessity. According to WHO [3], the prevalence of hypertension is around $40 \%$ in the low-, and middle-income countries, and $\sim 34 \%$ in the Western countries, with a slightly lower rates in women (still $>30 \%$ ) all over the world [3]. Hence, effective diagnosis and treatment is a necessity. In a Chi nese rural population, more than $44 \%$ use a preparation of herbal compounds that contains reserpine [6].

In India, an initiative by the kidney help trust has led to the screening of the entire population in $\sim 56$ villages and hamlets around Chennai, India, since 1995, for both diabetes and hypertension [4-10]. Hypertension was/is treated with reserpine $(0.1 \mathrm{mg})$ and hydralazine in the brand Adelphane [7-11] or Adelphane esridex [7-12]. As hypertension is a chronic condition, these patients remain on reserpine for several years. Reserpine [4-13] used in this community health initiative as well as in the Chinese rural population [6] is a historical entity. It is a plant alkaloid purified from the roots (common name - snake root - "sarpakhanda") of the plant Rauwolfia serpentina [14-16] and is used for hypertension [16] and as an antipsychotic [17]. From ancient times, Indians have used the snakeroot to treat snake bite, insanity, insomnia and as a tranquilizer $[14,15]$. Reserpine acts by down regulation of biogenic amines (dopamine, serotonin, epinephrine and norephineprine) through 
the inhibition of vesicular monoamine transporter (VMAT) [18-20]. In the 1950's, reserpine was introduced along with chlorpromazine as an antipsychotic [21]. The dosage given was in mg quantities. Though solid reports are hard to find [21], reserpine is believed to cause severe depression and is rarely prescribed except as second or third line drug for hypertension [22]. The dosage of reserpine needed to treat hypertension is very small, between $0.1 \mathrm{mg}$ and $0.6 \mathrm{mg} /$ day [7-22]. Reserpine is contraindicated in subjects with depression. Patients on reserpine are monitored for depression. Reserpine has been a victim of negative publicity [23]. It has been reported to cause severe depression, eventually leading to suicide [15]. As this is an effective and affordable drug for a huge population in low and middle income countries, it is important to ascertain whether reserpine actually causes depression in hypertensive patients on this drug regimen.

\section{Materials and Methods}

\section{Study design}

Subjects: Age, sex, education and socioeconomic background matched control (not hypertensive) and hypertensive patients on Adelphane [11] or Adelphane Esidrex [12] from Novaritis, Basel, Switzerland for several years were recruited. The International Standard Sri Ramachandra University Institute Ethics Committee clearance was obtained before the study was initiated and patient consent was acquired. The control group $(\mathrm{N}=105)$ and the Adelphane (reserpine) treated group $(\mathrm{N}=104)$ were from the same locality. This was a blinded cross-sectional study. More than $80 \%$ patients were on the drug for more than one year while $~ 33 \%$ were taking the drug for more than 10 years. Around 1.4\% were taking the reserpine-based drug for more than 18 years.

Period: The study took almost one year to complete. The field visits and data collection took one year. Further, data consolidation and analysis took another six months. On the whole, it was started in May 2015 and ended in December 2016.

Hypertension treatment: The Kidney Help Trust of Chennai has been using reserpine as Adelphane $(0.1 \mathrm{mg}$ reserpine and $10 \mathrm{mg}$ of hydralazine) [11] or Adelphane Esidrex (has 10mg of hydrochlorothiazide added to Adelphane) [12] manufactured and sold by Novaritis, Switzerland to treat hypertension in patients in 56 villages and hamlets around Chennai, India from 1995 onwards. The dosage varies from 1 tablet to 4 tablets per day depending upon the condition of the patient. The drug is very effective at the given dose for a very long period (in years) and is well tolerated by the patients.

Depression evaluation: Depression in both the groups, patients and controls, was evaluated using the Hamilton Depression Rating Scale-17 items version [24] and scored. Further, based on the scores they were categorized according to the severity of depression $[25,26]$.

Statistical analysis: Statistical analysis of the scores obtained through the HDRS was done using Sigma Plot 10.0. Statistical significance was determined by Students t-test and Mann-Whitney Rank Sum Test.

\section{Results}

Control group (105) and patients receiving reserpine (104) were screened for depression with the Hamilton Depression Rating scale (17-items Version). The results obtained by the HDRS [24] were classified into normal and various levels of depression judged on the score-based categorization $[25,26]$ (Table 1,2). Overall, there was no difference between the control and patients on reserpine (Figure 1). In the two groups, $38.09 \%$ of control and $38.46 \%$ of treated patients were normal (Figure 2), while $38.09 \%$ of control and $48.07 \%$ of treated had mild depression (Figure 3). $23.8 \%$ of control and $13.46 \%$ of treated belonged to moderate depression category (Figure 4) (Table 1,2). There was no one with severe or very severe depression in either control or treated of both genders. No significant difference was observed between the two groups. Of the approximately 2000 or so patients on reserpine under kidney help trust in Chennai, India, only three had been removed from reserpine, confirming that reserpine is an inexpensive and effective antihypertensive drug.

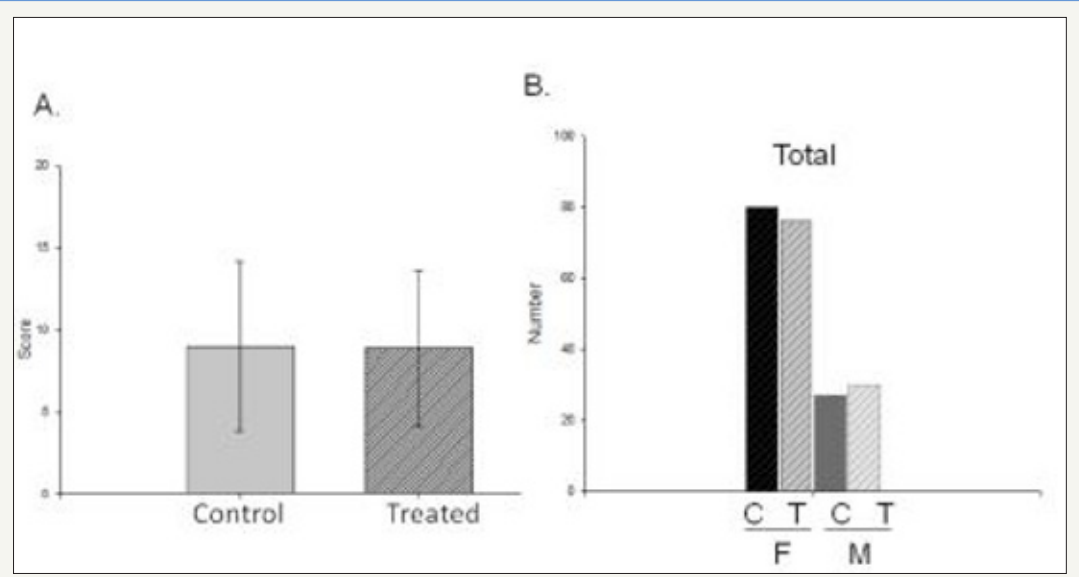

Figure 1: No depression due to reserpine.

A. No significant difference between the (Cumulative) Control $(\mathrm{N}=105)$ and treated $(\mathrm{N}=104)]$ in the HDRS score.

B. Number of subjects distribution based on genders -Male and females for both control and treated. 


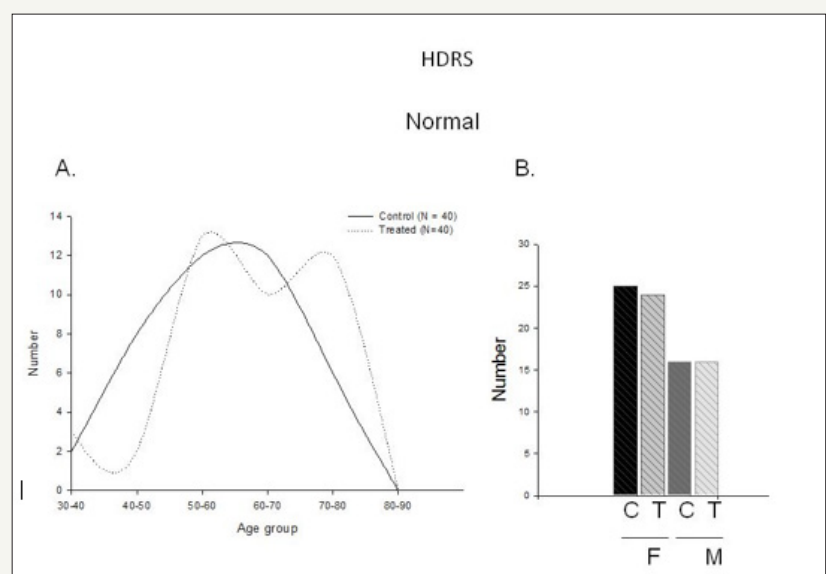

Figure 2: Normal range HDRS score with reserpine

A. $\quad$ No difference in HDRS score between Control (black) $(\mathrm{N}=40)$ and reserpine treatment (dotted line) $(\mathrm{N}=40)$.

B. Number of subjects distribution based on genders -Male and females for both control and treated.

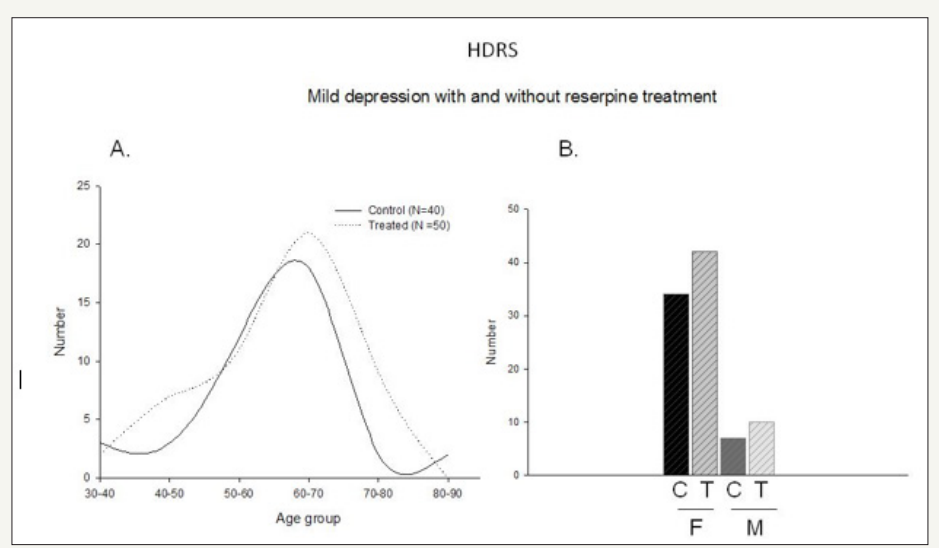

Figure 3: Mild depression comparison

A. Increase in mild depression in patients taking reserpine Control (black) $(\mathrm{N}=40)$ and reserpine treatment (dotted line) $(\mathrm{N}=50)$.

B. Number of subjects distribution based on genders -Male and females for both control and treated.



Figure 4: Moderate depression reduction

A. Reduction in moderate depression upon reserpine treatment. Control (black) $(\mathrm{N}=25)$ and reserpine treatment (dotted line) $(\mathrm{N}=14)$.

B. Number of subjects distribution based on genders -Male and females for both control and treated. 
Table 1: *HDRS scale-based depression classification.

\begin{tabular}{|c|c|}
\hline Score & Classification \\
\hline $0-7$ & Normal \\
\hline $8-13$ & Mild depression \\
\hline $14-18$ & Moderate depression \\
\hline $19-22$ & Serve depression \\
\hline$\geq 23$ & Very Serve depression \\
\hline
\end{tabular}

* - Hamilton depression rating scale

Table 2: Distribution of patients across different categories of hypertension.

\begin{tabular}{|c|c|c|c|}
\hline Score & Classification & Control & Reserpine Treatment \\
\hline $0-7$ & Normal & 40 & 40 \\
\hline $8-13$ & Mild depression & 40 & 50 \\
\hline $14-18$ & $\begin{array}{c}\text { Moderate depres- } \\
\text { sion }\end{array}$ & 25 & 14 \\
\hline
\end{tabular}

\section{Discussion}

Hypertension is one of the major non-communicable diseases of this age with the prevalence between $30-40 \%$. Without any symptoms, it is a silent killer causing sudden deaths. Given the enormous prevalence, morbidity, mortality, social, financial and economic burden on mankind, it becomes imperative to address this problem on a war footing.

A major initiative is by the kidney help trust in Chennai, which has been screening rural population for diabetes and hypertension from 1995 onwards and providing treatment for persons with these diseases [4-11]. The antihypertensive drug used is Adelphane. This is the least expensive hypertensive medication and also the most effective, given that antihypertensive drugs need to be taken lifelong and cost is a major factor [4-10]. Hence, reserpine is the drug of choice for the poor [4-11]. One major concern about reserpine is the possibility of it causing severe depression. One of the major reasons for reserpine not being widely used is this alleged negative effect $[15,23]$. But, evidence-based reports are hard to find [21]. Even so, depression is reported only in the high doses used to treat psychosis. In mice studies, at a low dosage of $1 \mathrm{mg} / \mathrm{kg}$ reserpine does not cause depression and the manic depression pathological marker mkb-1 is not induced, but at the dosage of $2 \mathrm{mg} / \mathrm{kg}$ both these effects are noticed [27]. It is widely in use, especially as an antihypertensive drug, even at a community level on [4-11] the low dosage of $0.1 \mathrm{mg}-0.6 \mathrm{mg}$ against hypertension with minimal side effects for several years and it reduces mortality when used as an antihypertensive [28].

Depression in patients on long-term reserpine treatment for hypertension was evaluated with HDRS. Overall, there was no difference in the scores between control and patients on reserpine (Figure 1A). Of the 105 control and 104 treated patients, 38\% (both control and treated) were normal (Figure $2 \mathrm{~A}$ ), 38\% of control and $48 \%$ of treated had mild depression (Figure $3 \mathrm{~A}$ ) while $23.8 \%$ of control and $13.4 \%$ of treated had moderate depression (Figure $4 \mathrm{~A}$ ). No one was found with severe or very severe depression in either control or treated group. Further, the profile did not show much difference either in the overall score level (Figure 1B) or across the spectrum of normal (Figure 2B), mild (Figure 3B) and moderate (Figure 4B) depression between males and females, though there were more females than males in both the control and treated cohorts. In order to reconfirm, around $50 \%$ of control and reserpine treated patients were retraced. While more than $80 \%$ of the patients were on reserpine for more than two years, 33\% were taking reserpine for more than 10 years. Around $1.4 \%$ were taking reserpine for more than 18 years. The blood pressure of control subjects was normal while the Adelphane/Adelphane esidrex treated patients had been brought down by $10 \mathrm{~mm} \mathrm{Hg}$ in both diastolic and systolic blood pressure (Table 3).

Table 3: Blood pressure of the control and treated (reserpine based) hypertensive patients.

\begin{tabular}{|c|c|c|c|c|c|c|}
\hline \multirow{4}{*}{ Description } & \multirow{2}{*}{\multicolumn{2}{|c|}{ Control }} & \multicolumn{4}{|c|}{ Treated } \\
\hline & & & \multicolumn{4}{|c|}{ Blood Pressure in mm Hg } \\
\hline & \multicolumn{2}{|c|}{ Blood pressure in mm $\mathrm{Hg}$} & \multicolumn{2}{|c|}{ Before starting of medication } & \multicolumn{2}{|c|}{ At the end of the current study } \\
\hline & Systolic & Diastolic & Systolic & Diastolic & Systolic & Diastolic \\
\hline Mean & 120 & 76 & 149 & 88 & 143 & 83 \\
\hline Median & 120 & 80 & 150 & 90 & 140 & 80 \\
\hline Std. Dev & 11.5 & 6 & 19 & 10 & 20 & 6 \\
\hline Maximum & 140 & 90 & 200 & 120 & 200 & 100 \\
\hline
\end{tabular}

Contrary to the suspected implications, reserpine seems to be safe for prolonged usage as an antihypertensive. This is further iterated by the usage of reserpine in $44 \%$ of rural Chinese population as an herbal compound preparation [6]. Moreover, reserpine has always been considered to be an effective antihypertensive, even for older patients [29]. In a situation where the world is aging, life expectancy is increasing, majority of the patients on reserpine treatment are between 50 and 70 years old in the poor, rural 
South Indian setting. This is another important caveat that needs to be considered, that is, increased normal health span due to longer lifespan.

Related to increased health span, it has been identified that reserpine could provide high quality lifespan extension in C. elegans [30,31]. In addition, reserpine was able to provide protection against dementia - Alzheimer disease (a geriatric disease affecting many old people, known to be a huge social and financial burden on society) causing, $A \beta$-induced toxicity manifested as progressive paralysis, in the C. elegans model [31-33]. Similarly, in the AD mouse model, Tg2576, expressing human mutant APP, which causes A $\beta$ aggregates formation and cognitive deficits at 11 months of age, reserpine reduces the $A \beta$ levels [34] and enhances working memory [35] in the 5XFAD AD model [36]. Further, reserpine is protective against another fatal neurodegenerative disease, amyotrophic lateral sclerosis, again in the C. elegans model [37]. Thus, in the model organism C. elegans, better health span and protection against two neurodegenerative disease-causing proteins could be achieved.

Hence, given the large scale of the hypertension problem that the world is facing, reserpine-based treatment shows a way to treat the disease safely, effectively and in an inexpensive manner where cost is a huge constraint in the low and middle income countries. However, during the initiation period, the patients need to be monitored. Another added advantage of taking reserpine could be a normal healthy life avoiding neurodegenerative diseases like Alzheimer disease.

\section{Acknowledgement}

The authors extend their heartfelt gratitude to Dr. Mani MK Managing Trustee, Kidney Help Trust Chennai for the constant support, guidance and critical comments and the employees of Kidney Help Trust who were instrumental in the identification and recruitment of the subjects. The authors thank Prof. Kanury Rao, Drug Discovery Research Center, The Translational Health Research Institute, India and Prof. M. Suresh Kumar, Department of Psychiatry, Sri Ramachandra University for the critical comments and Prof Sakthisekaran, Department of Community Medicine, Sri Ramachandra University for the discussions and suggestions. The authors declare no conflict of interest.

Note: Midway through this study, due to non-availability of Adelphane/Adelpane esidrex the hypertensive patients were switched to Arkamin.

\section{References}

1. World Health Organization (2011) Global status report on noncommunicable diseases 2010. World Health Organization, Geneva, Switzerland.

2. World Health Organization (2008) Global health observatory data repository [online database]. World Health Organization, Geneva, Switzerland.

3. World Health Organization (2013) A global brief on hypertension: Silent killer, global public health crisis, p. 40.

4. Mani MK (2003) Prevention of chronic renal failure at the community level. Kidney Int Suppl 83: S86-S89.
5. Chan M (2013) A Global brief on hypertension. Silent killer, global public health crisis, p. 5

6. Zou G, Zhang Z, Walley J, Gong W, Yu Y, et al. (2015) Use of medications and lifestyles of hypertensive patients with high risk of cardiovascular disease in rural China. PLoS ONE 10(5): e0124484.

7. Mani MK (2005) Experience with a program for prevention of chronic renal failure in India. Kidney Int Suppl (94): S75-S78.

8. Datta M, Mani MK (2005) Community based approach to prevention of chronic kidney disease: the Chennai experience. In: El Nahas M (Ed.) Kidney diseases in the developing world and ethnic minorities. Taylor and Francis, New York, USA, pp. 395-409.

9. Mani MK (2006) Nephrologists san frontierers: Preventing chronic kidney disease on a shoestring. Kidney International 70(5): 821-823.

10. Mani MK (2010) A glimmer of hope for prevention. National Medical Journal of India 23(2): 109-110.

11. https://www.1mg.com/drugs/adelphane-esidrex-tablet-180265

12. https://www.drugs.com/pro/reserpine.html

13. Lele R (2010) Beyond reverse pharmacology: Mechanism-based screening of ayurvedic drugs. Journal of Ayur-veda and Integrative Medicine 1(4): 257-265.

14. Shastry JLN (2015) Illustrated dravyaguna VI jnana. Study of the Essential Medicinal Plants in Ayurveda. Chaukhamba Orientalia, India.

15. http://easyayurveda.com/2013/10/18/sarpagandha-rauwolfia-serpentina-benefits-side-effects-ayurveda-details/

16. Vakil RJ (1949) A clinical trial of rauwolfia serpentina in essential hypertension. Bri Heart J 11(4): 350-355.

17. Bleuler M, Stoll WA (1955) Clinical use of reserpine in psychiatry: Comparison with chlorpromazine. Ann New York Acad Sci 61(1): 167-173.

18. Purves D (2001) Neurotransmitters, chap 1.6. Neuroscience, $\left(2^{\text {nd }}\right.$ edn). Sinauer Associates, USA.

19. Sulston JE, Dew M, Brenner S (1975) Dopaminergic neurons in the nematode Caenorhabditis elegans. J Comp Neurol 163(2): 215-226.

20. Duerr JS, Frisby DL, Gaskin J, Duke A, Asermely K, et al. (1999) The cat-1 gene of Caenorhabditis elegans encodes a vesicular monoamine transporter required for specific monoamine-dependent behaviors. J Neurosci 19(1): 72-84

21. Nur S, Adams CE (2016) Chlorpromazine versus reserpine for schizophrenia. Cochrane Database Syst Rev 4: CD012122.

22. Shamon SD, Perez MI (2016) Blood pressure-lowering efficacy of reserpine for primary hypertension. Cochrane Database Syst Rev 4: CD007655.

23. Lopez-Munoz F, Bhatara VS, Alamo C, Cuenca E (2004) Historical approach to reserpine discovery and its introduction in psychiatry. Actas Esp Psiquiatr 32(6): 387-395.

24. Hamilton M (1960) A rating scale for depression. J Neurol Neurosurg Psychiatry 23: 56-62.

25. Endicott J, Cohen J, Nee J, Fleiss S, Sarantakos (1981) Hamilton depression rating scale. Archives of General Psychiatry 38(1): 98-103.

26. Zimmerman M, Martinez JH, Young D, Chelminski I, Dalrymple K (2013) Severity classification on the hamilton depression Rating Scale. J Affect Disord 150(2): 384-388.

27. Lee HR, Hwang I, Kim JE, Cho SI, Lee YJ, et al. (2012) Altered expression of $\gamma$-secretase components in animal model of major depressive disorder induced by reserpine administration. Laboratory Animal Research 28(2): 109-114. 
28. Curb JD, Schneider K, Taylor JO, Maxwell M and Shulman N (1988) Antihypertensive drug side effects in the hypertension detection and follow-up program. Hypertension 11(3 Pt 2): 1151-1155.

29. Feigenbaum LJ (1993) Reserpine and thiazide for hypertension-an inexpensive therapy for older patients. Western Journal of Medicine 158(5): 535.

30. Srivastava D, Arya U, Soundar Rajan T, Dwivedi H, Kumar S (2008) Reserpine can confer lifespan extension in C. elegans. Biogerontology 9(5): 309-316

31. Saharia K, Arya U, Kumar R, Sahu R, Das CK, et al. (2012) Reserpine modulates neurotransmitter release to extend lifespan and alleviate age-dependent $A \beta$ proteotoxicity. Experimental Gerontology 47(2): 188-197.

32. Arya U, Dwivedi H, Subramaniam JR (2009) Reserpine ameliorates A $\beta$ toxicity in the Alzheimer's disease model in C. elegans. Exp Gerontol 44(6-7): 462-466.

33. Saharia K, Kumar R, Gupta K, Mishra S, Subramaniam JR (2016) A novel way of amelioration of $A \beta$ induced toxicity in Caenorhabditis elegans. Annals of Neuroscience 23(3): 149-154.
34. Go J, Cho SI, Kim JI, Lee YJ, Kwak MH, et al. (2013) Effect of reserpine on the behavioral defects, $A \beta-42$ deposition and NGF Metabolism in Tg2576 transgenic mouse model for alzheimer's disease. J Life Sci 23(6): 812824.

35. Vasantharaja R, Kumar A, Kumar A, Subramaniam JR (2016) Reserpine improves working memory. Journal of Behavioral and Brain Science 6(3): 107-112.

36. Oakley H, Cole SL, Logan S, Maus E, Shao P, et al. (2006) Intraneuronal beta-amyloid aggregates, neurodegeneration, and neuron loss in transgenic mice with five familial Alzheimer's disease mutations: potential factors in amyloid plaque formation. J Neurosci 26(40): 10129-10140.

37. Tauffenberger A, Julien C, Parker JA (2013) Evaluation of longevity enhancing compounds against transactive response DNA-binding protein-43 neuronal toxicity. Neurobiol Aging 34(9): 2175-2582.



Creative Commons Attribution 4.0

International License

For possible submissions Click Here
Submit Article

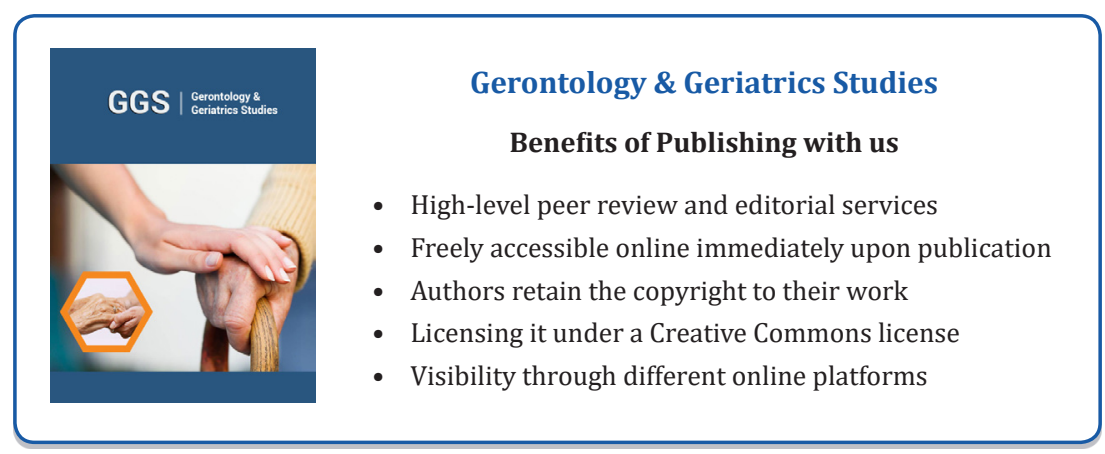

